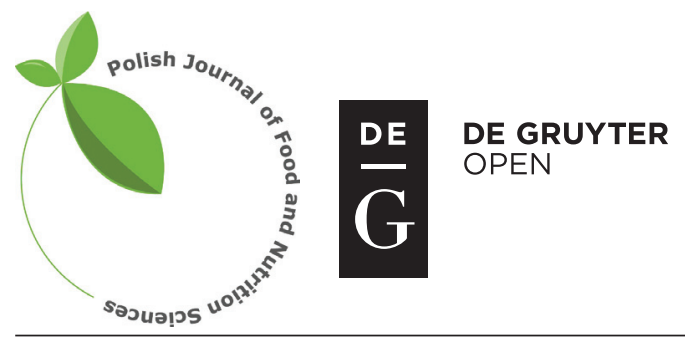

Pol. J. Food Nutr. Sci., 2016, Vol. 66, No. 2, pp. 77-84

10.1515/pjfns-2015-0027

Original article

Section: Food Quality and Functionality

\title{
Oxidative Stability of Lipid Fraction of Cookies Enriched with Chokeberry Polyphenols Extract
}

\author{
Malgorzata Bialek ${ }^{1}$,Jaroslawa Rutkowska ${ }^{1 *}$, Agnieszka Bialek ${ }^{2}$, Agata Adamska ${ }^{2}$ \\ ${ }^{I}$ Faculty of Human Nutrition and Consumer Sciences, Warsaw University of Life Sciences (WULS-SGGW), \\ Nowoursynowska 159c str., 02-776 Warsaw, Poland \\ 2Department of Bromatology, Faculty of Pharmacy with the Laboratory Medicine Division, \\ Medical University of Warsaw, Banacha 1 str., 02-097 Warsaw, Poland
}

Key words: oxidative stability, cookies, chokeberry, natural antioxidants

The effect of incorporation of different contents of chokeberry polyphenols extract (CPE) into cookie recipe on the oxidative stability of the lipid fraction of cookies was determined in the study. Margarine and butter cookies with different contents of CPE were prepared. Contents of primary (Peroxide value, PV) and secondary (Anisidine value, AV; thiobarbituric acid reactive substances, TBARS) lipid oxidation products and fatty acids profile were measured during storage. Different course of lipid degradation depending on both polyphenols content and storage time was shown. Cookies were characterised by a low PV (1.45 and $4.90 \mathrm{meq}$ of $\mathrm{O} / \mathrm{kg}$ of fat in margarine and butter cookies, respectively). The AV increased during storage both in margarine and in butter cookies. Losses of PUFA in margarine cookies $(0.34 \%)$ apply mainly to $\alpha$-linolenic acid. It appears safe to incorporate $100 \mathrm{mg}$ and $250 \mathrm{mg}$ of CPE into margarine cookies stored for 9 weeks and $1000 \mathrm{mg}$ of CPE into butter cookies stored for 9 weeks. The incorporation of $1000 \mathrm{mg} \mathrm{CPE}$ into cookies resulted in a significant increase in the intensity of astringent taste, acidic taste, off-taste and off-flavour.

\section{INTRODUCTION}

Oxidation of lipids is undoubtedly one of the most common processes in the food system. The structure of foods is changing during processing, as a result of which lipids may become more exposed to oxygen. The main effect of lipid oxidation is the development of off-flavours and odours which shorten the shelf-life of foodstuffs and make them unacceptable for consumption. At the same time, the nutritional value and safety of foods decrease owing to the formation of deleterious primary and secondary compounds [Frankel, 1996], which are associated with a number of degenerative processes and disorders, such as cancer, inflammation and cardiovascular diseases [Marquez-Ruiz et al., 2008]. Effective counteracting food lipid oxidation includes the use of antioxidants.

Since the beginning of the twentieth century synthetic antioxidants, such as butylated hydroxytoluene (BHT) and butylated hydroxyanisole (BHA), have been commonly used. Although they are relatively cheap and efficient in reducing the rate of oxidative processes, their use is questionable because of concerns over their toxicity [Mildner-Szkudlarz et al., 2009]. Another drawback of these antioxidants is that they are volatile and readily decompose at high temperatures [Martinez-Tome et al., 2001]. Therefore a worldwide trend is observed aimed at minimizing or even avoiding the use

\footnotetext{
* Corresponding Author: Tel.: + 4822 5937072; Fax: + 48225937071

E-mail: jaroslawa_rutkowska@sggw.pl (Prof. Jaroslawa Rutkowska)
}

of synthetic additives and at replacing them with naturally occurring ones. Natural antioxidants are presumed to be safe since they occur in different plant foods as secondary metabolites. The compounds isolated directly from different parts of fruits and vegetables have become significant in food production as alternatives to synthetic antioxidants [Valenzuela et al., 2003].

Application of some natural antioxidants to bakery products has been reported in several studies. Various polyphenols originating from plants (from apple, green tea, sweet potato, drumstic (Moringa oleifera), Garcinia), spices (cinnamon, cardamom, cloves, ginger, anise, rosemary, black cumin, curry, turmeric, coriander, sage), and cereal products (amaranth, oatmeal, rice bran extracts, buckwheat) had been successfully used as inhibitors of the oxidation process during storage [Bhanger et al., 2008; Vergara-Valencia et al., 2007; Mildner-Szkudlarz et al., 2009; Abdel-Samie et al., 2010; Huang \& Li, 2011; Badei et al., 2002; Nanditha et al., 2009; Basuny et al., 2012; Sudha et al., 2007; Ishida et al., 2003; Reddy et al., 2005; Isobe et al., 2004; Kozlowska et al., 2014].

As previously reported, berries are typical components of a diet of the North-European consumers. Among them, chokeberry (Aronia melanocarpa) is the richest source of polyphenols (the content ranges from 2 to $8 \mathrm{~g}$ per $100 \mathrm{~g}$ of dry matter), which possess a strong antioxidative activity [Oszmianski \& Wojdylo, 2005]. Chokeberry contains 9 flavonoids (e.g. rutin, hyperoside, isoquercetin), 4 anthocyanins (cyanidin 3-O-glucoside, cyanidin 3-O-galactoside, cyanidin 
3-O-arabinoside, cyanidin 3-O-xyloside), 2 phenolic acids (chlorogenic acid and neochlorogenic acid) and 5 quercetins (quercetin 3-O-glucoside, quercetin 3-O-galactoside, quercetin 3-O-rutinoside, quercetin 3-O-robinoside, quercetin 3-O-vicianoside) [Lee et at., 2014; Šavikin et al., 2014; Taheri et al., 2013]. Phenolic compounds present in chokeberry fruits are responsible for many health benefits. Recently Šavikin et al. [2014] revealed their cytotoxic activity against cervix carcinoma, melanoma, colon and chronic myelogenous leukemia cell lines. Other authors indicated their cardioprotective, hepatoprotective and antidiabetic properties [Broncel et al., 2010; Denev et al., 2012]. Chokeberry fruits are commonly used for the production of juices, syrups, teas, jams, jellies and wines. Also chokeberry by-products - pomaces remaining after juicing process, are used as an enriching ingredient in bread making and sausage production [Bialek et al., 2012]. The addition of chokeberry fruits or extracts to high-fat bakery products to inhibit the oxidation process seems to be very promising.

Consumers' awareness regarding prevention of cancer and other diet-related diseases has greatly increased in recent years. It is common knowledge that among the main causes of the above-mentioned disorders are formation of free radicals and oxidation processes [Marquez-Ruiz et al., 2008]. Therefore, a growing interest is observed in antioxidant-supplemented foods. The aim of producers, processors and scientists has been to increase the nutritional value of such food products. Foodstuffs improved in this way can be produced on the commercial scale and offer not only convenience but also health-promoting properties to consumers. However, to produce the expected effects, enriched confectionery products should not only be rich in nutritive compounds, but also willingly consumed.

In the present study, a chokeberry polyphenol extract (CPE) was used as a source of antioxidants in cookies prepared with two different types of fat. The main aim of this study was to investigate the oxidative stability of fats in cookies prepared with different contents of this ingredient.

\section{MATERIALS AND METHODS}

\section{Materials}

Ingredients for cookies manufacturing (wheat flour, butter, margarine, eggs, sugar powder) were purchased at the local market. A chokeberry polyphenol extract containing 52.6\% $(\mathrm{w} / \mathrm{w})$ of polyphenols was obtained free of charge from Agropharm company (Tuszyn, Poland). Detailed phenolic profile is presented in Table 1 [Scientific expert opinion by Prof. Oszmianski]. All other solvents and reagents were of analytical grade and were purchased from Sigma Aldrich (Poland).

\section{Preparation of a solution of a chokeberry polyphenol extract}

A solution of citric acid was prepared by dissolving $3.58 \mathrm{~g}$ of citric acid in $225 \mathrm{~mL}$ of water. Doses of $100 \mathrm{mg}, 250 \mathrm{mg}$ and $1000 \mathrm{mg}$ of CPE were dissolved in $10 \mathrm{~mL}$ of the earlier prepared citric acid solution in order to stabilize and uniformly mix the formulation with dough.

\section{Preparation of cookies}

Cookies were prepared according to our own recipe in 4 variants differing in the content of CPE: with $100 \mathrm{mg}$,
TABLE 1. Content of phenolic compounds in chokeberry polyphenol extract (CPE) (acc. to Oszmianski).

\begin{tabular}{lc}
\hline Phenolic constituents & Mean $\pm \mathrm{SD}(\%)$ \\
\hline Phenolic acids (total): & 12.27 \\
Neochlorenic acid & $6.03 \pm 3.39$ \\
Chlorogenic acid & $6.24 \pm 1.91$ \\
Flavonols & $1.95 \pm 1.00$ \\
Antocyanins (monomeric) (total): & 23.52 \\
Cya-3-galactoside & $15.53 \pm 5.08$ \\
Cyan-3-glucoside & $0.79 \pm 0.24$ \\
Cyan-3-arabinoside & $6.17 \pm 2.44$ \\
Cyan-3-xyloside & $1.03 \pm 0.46$ \\
Procyanidins & $14.9 \pm 2.66$ \\
Total phenolic compounds & 52.64 \\
\hline
\end{tabular}

$250 \mathrm{mg}$ and $1000 \mathrm{mg}$ of CPE per $\mathrm{kg}$ of dough, and control (0 mg of CPE). The content of polyphenols in each sort of cookies was $52.6 \mathrm{mg}, 131.5 \mathrm{mg}, 526 \mathrm{mg}$ and $0 \mathrm{mg}$ per $\mathrm{kg}$ of dough, respectively. The following proportions of ingredients were used to prepare cookies: wheat flour $(500 \mathrm{~g})$, powdered sugar $(250 \mathrm{~g})$, fat - margarine or butter $(312 \mathrm{~g})$, egg yolks (4 pcs). Fat (butter or margarine) was added to sifted wheat flour and minced with a mixer (type HR 7677/A, Phillips, Austria), then egg yolks and powdered sugar were added. All ingredients were kneaded until completely merged. The dough was sheeted to a thickness of $5 \mathrm{~mm}$ and cut into circular shapes using a cookie cutter with $50 \mathrm{~mm}$ diameter. Then cookies were placed on a tray and baked at $180^{\circ} \mathrm{C}$ for $15 \mathrm{~min}$ in a convection oven with forced air circulation (Electrolux AR 85, Italy). Average weight of one cookie was $14.5 \pm 0.05 \mathrm{~g}$. Cooled cookies were packed in non-hermetized containers suitable for contact with food and stored at $19^{\circ} \mathrm{C}$, without access to light for 18 weeks (to mimic in-shop storage conditions). Samples for analysis were collected after $0,3,6$, $9,12,15$ and 18 weeks of storage.

\section{Methods}

\section{Oxidative stability}

Lipids were extracted according to Polish Standard [PNA 88021:1971] by the Soxhlet method using hexane as an extracting solvent. Stability of the lipid fraction of cookies was analysed periodically by determining the peroxide value (PV), anisidine value $(\mathrm{AV})$, concentration of thiobarbituric acid reactive substances (TBARS) and by TOTOX value. PV was assayed according to ISO 2001:3960 by titration method. The results were expressed as meq of $\mathrm{O} / \mathrm{kg}$ of fat. The AV was determined using a Milton Roy spectrophotometer at $350 \mathrm{~nm}$ according to ISO 2006:6885. TBARS content was determined spectrophotometrically at $532 \mathrm{~nm}$ according to the modified method of Ohkawa et al. [1979]. Results were expressed as $\mu \mathrm{g} \mathrm{MDA} / \mathrm{g}$ of fat. TOTOX was calculated from the following formula: TOTOX $=2 \mathrm{PV}+\mathrm{AV}$. The reference value for TOTOX was calculated by substituting the permissible PV and proposed $\mathrm{AV}$ into the formula.

\section{FA content}

Methyl esters of fatty acids (FAME) were prepared by transmethylation of fat samples using a mixture of con- 
centrated $\mathrm{H}_{2} \mathrm{SO}_{4}(95 \%)$ and methanol according to AOCS 2000 Official Method Ce 2-66. The FAMEs were analysed by gas chromatography (GC) using an Agilent 6890N (USA) chromatograph equipped with flame ionization detector (FID), a split/splitless injector, operated with a split ratio of 1:50, and a capillary column with a stationary phase of high polarity $(100 \mathrm{~m} \times 0.25 \mathrm{~mm}$ I.D., film thickness $0.1 \mu \mathrm{m}$; Rtx 2330 Restek). The analyses involved a programmed run with temperature ramps. The oven temperature was initially $120^{\circ} \mathrm{C}$ for $12 \mathrm{~min}$ then ramped to $155^{\circ} \mathrm{C}$ at $5^{\circ} \mathrm{C} / \mathrm{min}$ and held for $50 \mathrm{~min}$. The temperature was then ramped again at $2^{\circ} \mathrm{C} /$ min to $210^{\circ} \mathrm{C}$ and held for $35 \mathrm{~min}$. Injector and detector temperatures were maintained at $250^{\circ} \mathrm{C}$, the carrier gas (helium) flow rate was $0.9 \mathrm{~mL} / \mathrm{min}$. Fatty acid composition of cookies was determined at the beginning and at the end of storage. Peak areas were corrected by the response factors for FAME responses of FID, and area\% of FAME was appropriately converted to weight $\%$ of FA. A butter reference standard (CRM 164; Commission of the European Communities, Community Bureau of Reference, Brussels, Belgium) was used to determine the recovery rates and correction factors for individual FAs in butter cookie samples while the Supelco 37 No. 47885-U standard (Sigma Aldrich) was applied for fatty acid identification and recoveries of FAME in margarine cookies. The contents of individual FAs were expressed as g/100 g FA.

\section{Sensory evaluation}

The sensory evaluation of fresh cookies was performed using the scaling method [Baryłko-Pikielna \& Matuszewska, 2014]. Ten experienced panellists (4 males and 6 females; 27-46 years of age) participated in the study. They scored each attribute on a $100 \mathrm{~mm}$ unstructured scale in marked borders prepared in accordance with Polish Standard [PN-ISO 4121: 1998]. The subjects were requested to evaluate the intensity of sensory attributes of samples three times in the following order: aroma (buttery, acidic and off-flavours), taste (buttery, sweet, acidic, astringent and off-taste), colour, crispness. Cookies were delivered in coded plastic containers in a random order. Every panellist was provided with spring water to rinse mouth between samples. The results from the unstructured scale were converted to numerical values (from 0 to 10 units).

\section{Statistical analysis}

All chemical analyses were conducted in triplicates. Data were reported as means \pm standard deviation (SD). All SD were within $3 \%$ of the reported mean values. Results of chemical analyses were subjected to two-way factorial ANOVA. STATISTICA 9.1PL software (StatSoft, Inc. (2010) was used, the level of $\mathrm{P}<0.01$ was considered significant. Results of sensory assessment were subjected to one-way ANOVA with the $\mathrm{P}<0.05$ significance level.

\section{RESULTS}

\section{Primary oxidation products in lipids extracted from cookies}

The average fat content was $25.3 \pm 0.7 \%$ in margarine cookies and $25.4 \pm 0.5 \%$ in butter cookies. Changes in the content of primary oxidation products expressed as PV are shown in Figure 1. The PV obtained from margarine cookies ranged from 0.57 to $1.45 \mathrm{meq}$ of $\mathrm{O} / \mathrm{kg}$ of fat. In cookies with $\mathrm{CPE}$, the highest increase in PV was determined after 9 weeks of storage. In the case of butter cookies, the concentration of primary lipid oxidation products assayed at the $9^{\text {th }}$ week of storage was in the range from 0.39 to $4.90 \mathrm{meq}$ of $\mathrm{O} / \mathrm{kg}$ of fat. PV value differed significantly regarding to content of CEP and storage time in margarine and butter cookies.

\section{Secondary oxidation products in lipids extracted from cookies}

Concentrations of secondary lipid oxidation products expressed as AV and TBARS are shown in Figure 2 and Figure 3 , respectively. The content of $p$-anisidine reacting substances was increasing during storage in both types of cookies and reached the maximum level after 18 weeks of storage. The AV in cookies prepared with margarine ranged from 4.70 to 22.92 , and in cookies with butter from 5.30 to 18.60 .

In margarine cookies, the extended time of storage was associated with increased concentration of secondary lipid oxidation substances measured as TBARS. In butter cookies, the maximum TBARS value was observed after the $9^{\text {th }}$ week of storage irrespectively of CPE content.

\section{TOTOX value of lipids extracted from cookies}

The calculated TOTOX values for lipids extracted from cookies are presented in Figure 4. In both types of cookies, the TOTOX values increased during storage, i.e. from 5.30 to 20.00 in butter cookies and from 4.70 to 25.81 in margarine cookies. The TOTOX values significantly differed according to both CPE content and time of storage in both types of cookies.

\section{Fatty acid composition of lipids extracted from cookies}

Results of FA profile analysis of experimental cookies are presented in Tables 2 and 3. The assayed FAs were classified into the following groups: SFA (saturated FA), MUFA (monounsaturated FA) and PUFA (polyunsaturated FA) in margarine cookies. In butter cookies SFA were divided into short chain saturated FA (SCSFA) and long chain saturated FA (LCFA) and also groups of odd- and branched chain FA (OBCFA) were isolated. The average content of PUFA in margarine cookies accounted for $15.69 \mathrm{~g} / 100 \mathrm{~g}$ FA while in butter cookies for only $5.18 \mathrm{~g} / 100 \mathrm{~g} \mathrm{FA}$.

\section{Interactions}

Significant $(\mathrm{P}<0.01) \mathrm{CPE}$ content $\mathrm{x}$ storage time interactions were found for PV and TBARS and for AV and TOTOX values in both types of cookies (data not shown).

\section{Sensory analysis by experts}

The results of sensory assessment of fresh cookies by experts are presented in Figure 5. Sensory rating differed regarding $\mathrm{CPE}$ content in both types of cookies. Intensity ratings of buttery flavour and taste, sweet taste as well as crispness decreased with increasing level of CPE in cookies. Increasing the content of CPE resulted in higher ratings of the intensity of acidic aroma and taste, colour, off-flavour and off-taste. 
M

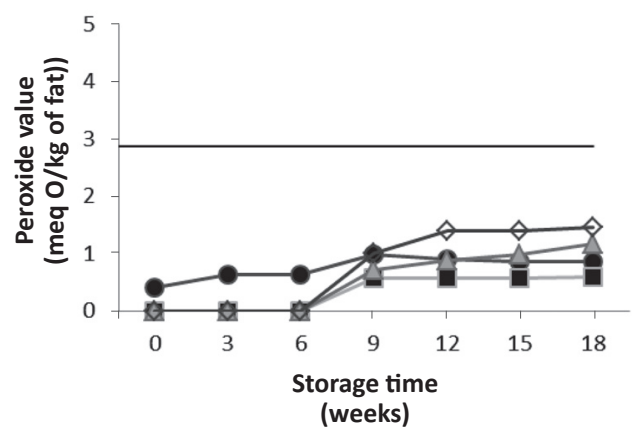

B

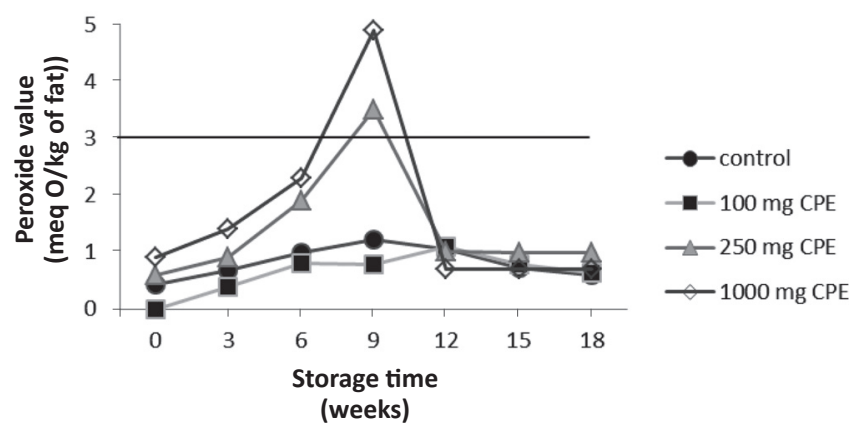

FIGURE 1. Changes in the content of primary oxidation products in cookies during storage ( $\mathrm{M}$ - margarine cookies, B - butter cookies). - Solid horizontal line - the acceptable PV value ( 3.0 meq $\mathrm{O} / \mathrm{kg}$ of fat)

M

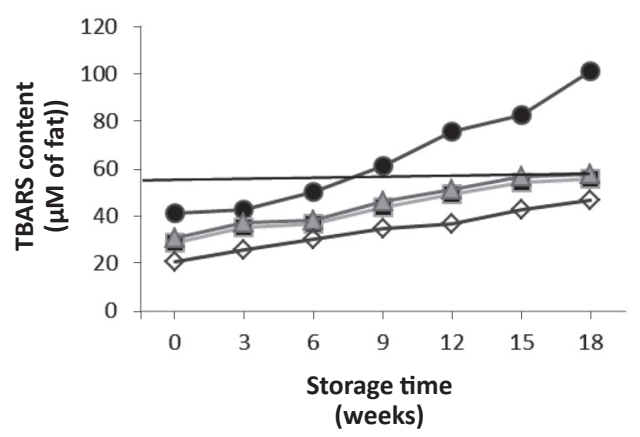

B

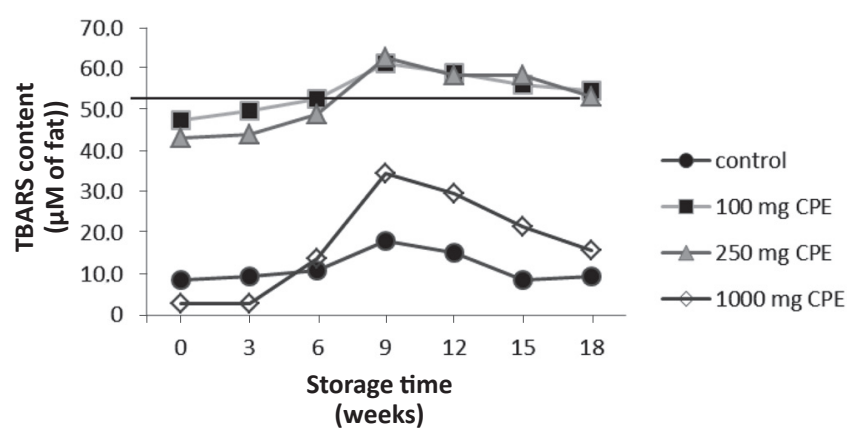

FIGURE 3. Changes in the TBARS content in cookies during storage ( $\mathrm{M}$ - margarine cookies, B - butter cookies).

- Solid horizontal line - the acceptable TBARS value $(57.6 \mu \mathrm{g} \mathrm{MDA} / \mathrm{g}$ of fat $)$
M

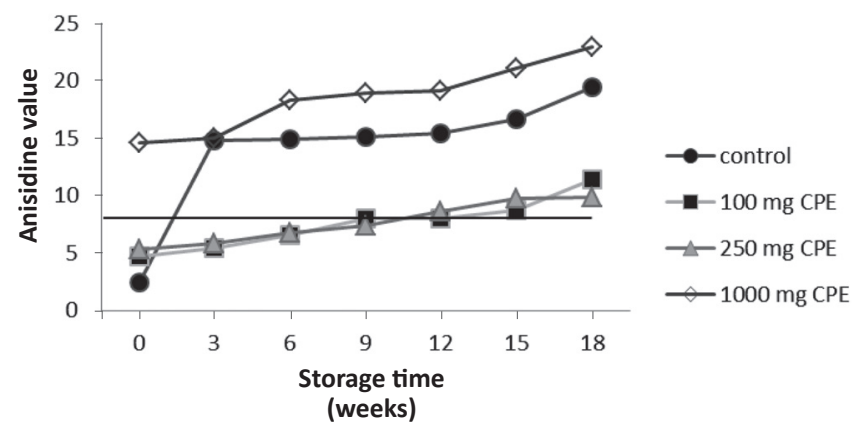

B

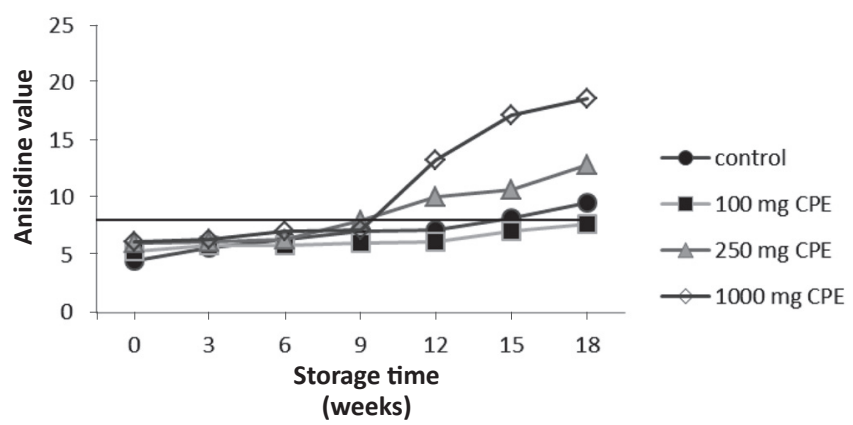

FIGURE 2. Changes in the anisidine value in cookies during storage ( $\mathrm{M}$ - margarine cookies, B - butter cookies).

- Solid horizontal line - the acceptable AV value (8.0)

M

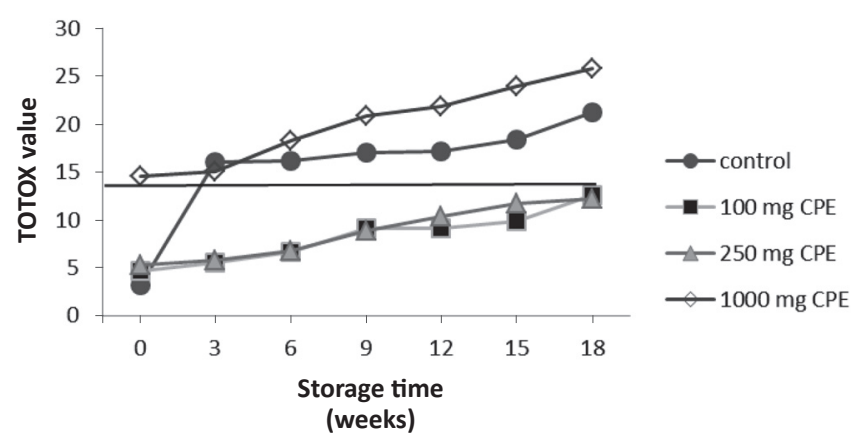

B

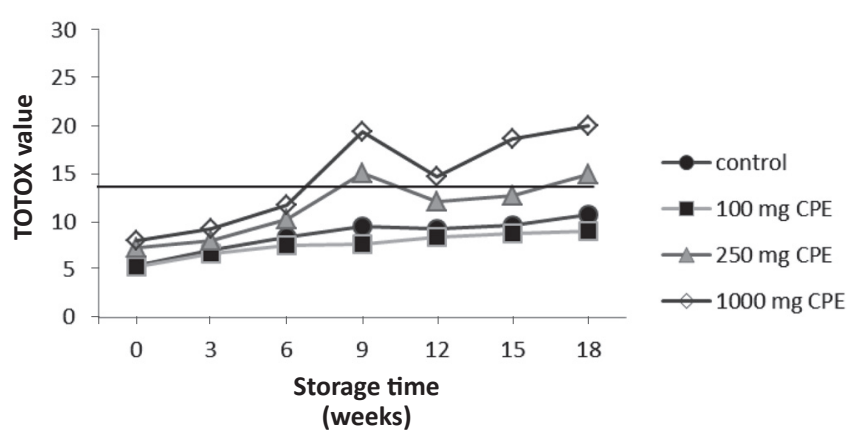

FIGURE 4. Changes in TOTOX value in cookies during storage ( $\mathrm{M}$ - margarine cookies, B - butter cookies).

- Solid horizontal line - the acceptable TOTOX value (14.0) 
TABLE 2. Fatty acid composition ${ }^{\mathrm{a}}$ of margarine cookies (g/100 g FA).

\begin{tabular}{l|c|c|c|c|c|c|c|c}
\hline \multirow{2}{*}{ Fatty acids } & \multicolumn{2}{|c|}{ Control } & \multicolumn{2}{c|}{$100 \mathrm{mg}$ CPE } & \multicolumn{2}{c|}{$250 \mathrm{mg}$ CPE } & \multicolumn{2}{c}{$1000 \mathrm{mg}$ CPE } \\
\cline { 2 - 9 } & 0 weeks & 18 weeks & 0 weeks & 18 weeks & 0 weeks & 18 weeks & 0 weeks & 18 weeks \\
\hline SFA & $46.45 \pm 0.45$ & $46.44 \pm 0.47$ & $46.19 \pm 0.40$ & $46.12 \pm 0.37$ & $45.29 \pm 0.56$ & $45.31 \pm 0.62$ & $45.04 \pm 0.33$ & $44.96 \pm 0.24$ \\
\hline MUFA & $37.84 \pm 0.36$ & $37.61 \pm 0.38$ & $37.79 \pm 0.21$ & $37.32 \pm 0.34$ & $38.15 \pm 0.45$ & $37.71 \pm 0.37$ & $38.06 \pm 0.19$ & $37.10 \pm 0.32$ \\
\hline PUFA: & $15.71 \pm 0.33$ & $14.83 \pm 0.27$ & $15.69 \pm 0.19$ & $15.51 \pm 0.23$ & $15.75 \pm 0.19$ & $15.66 \pm 0.13$ & $15.83 \pm 0.14$ & $15.64 \pm 0.21$ \\
C18:2 9c 12c & $12.24 \pm 0.09$ & $11.50 \pm 0.10$ & $12.35 \pm 0.09$ & $12.33 \pm 0.06$ & $12.42 \pm 0.03$ & $12.41 \pm 0.01$ & $12.50 \pm 0.09$ & $12.10 \pm 0.13$ \\
C18:3 9c 12c 15c & $3.25 \pm 0.03$ & $3.05 \pm 0.07$ & $3.24 \pm 0.09$ & $3.10 \pm 0.05$ & $3.23 \pm 0.07$ & $3.07 \pm 0.09$ & $3.26 \pm 0.04$ & $3.19 \pm 0.05$ \\
\hline
\end{tabular}

aValues are expressed as means \pm SD of 3 independent assays. SFA - saturated fatty acids, MUFA - monounsaturated fatty acids, PUFA - polyunsaturated fatty acids.

TABLE 3. Fatty acid composition ${ }^{\mathrm{a}}$ of butter cookies ( $\mathrm{g} / 100 \mathrm{~g}$ FA).

\begin{tabular}{l|rr|r|r|r|r|r|r}
\hline \multirow{2}{*}{ Fatty acids } & \multicolumn{2}{|c|}{ Control } & \multicolumn{2}{c|}{$100 \mathrm{mg}$ CPE } & \multicolumn{2}{c|}{$250 \mathrm{mg}$ CPE } & \multicolumn{2}{c}{$1000 \mathrm{mg}$ CPE } \\
\cline { 2 - 9 } & \multicolumn{1}{c|}{0 weeks } & \multicolumn{1}{c|}{18 weeks } & \multicolumn{1}{c|}{0 weeks } & \multicolumn{1}{c|}{18 weeks } & \multicolumn{1}{c}{0 weeks } & \multicolumn{1}{c}{18 weeks } & 0 weeks & \multicolumn{1}{c}{18 weeks } \\
\hline SCSFA & $13.83 \pm 0.09$ & $13.75 \pm 0.10$ & $13.65 \pm 0.21$ & $13.59 \pm 0.27$ & $13.80 \pm 0.29$ & $13.84 \pm 0.34$ & $13.54 \pm 0.11$ & $13.56 \pm 0.15$ \\
\hline LCSFA & $50.10 \pm 0.13$ & $49.73 \pm 0.11$ & $49.93 \pm 0.37$ & $49.90 \pm 0.31$ & $49.84 \pm 0.45$ & $49.83 \pm 0.39$ & $50.04 \pm 0.32$ & $50.00 \pm 0.43$ \\
\hline OBCFA & $2.07 \pm 0.01$ & $2.05 \pm 0.05$ & $2.06 \pm 0.02$ & $2.06 \pm 0.02$ & $2.08 \pm 0.03$ & $2.00 \pm 0.01$ & $2.05 \pm 0.02$ & $1.98 \pm 0.01$ \\
\hline MUFA: & $27.13 \pm 0.23$ & $26.90 \pm 0.34$ & $26.92 \pm 0.16$ & $26.84 \pm 0.19$ & $27.39 \pm 0.15$ & $26.97 \pm 0.17$ & $27.50 \pm 0.07$ & $26.15 \pm 0.10$ \\
C18:1 11 $t$ & $1.93 \pm 0.05$ & $1.94 \pm 0.07$ & $1.95 \pm 0.04$ & $1.88 \pm 0.08$ & $1.97 \pm 0.01$ & $1.94 \pm 0.03$ & $1.97 \pm 0.09$ & $1.87 \pm 0.05$ \\
C18:19c & $20.99 \pm 0.19$ & $20.90 \pm 0.13$ & $21.02 \pm 0.17$ & $20.83 \pm 0.20$ & $21.16 \pm 0.25$ & $20.87 \pm 0.21$ & $21.38 \pm 0.14$ & $20.08 \pm 0.19$ \\
PUFA: & $5.28 \pm 0.07$ & $5.14 \pm 0.09$ & $5.02 \pm 0.12$ & $4.88 \pm 0.09$ & $5.39 \pm 0.05$ & $5.11 \pm 0.07$ & $5.46 \pm 0.05$ & $5.16 \pm 0.07$ \\
C18:2 9c 12c & $3.35 \pm 0.08$ & $3.20 \pm 0.02$ & $3.09 \pm 0.03$ & $2.99 \pm 0.02$ & $3.41 \pm 0.03$ & $3.36 \pm 0.01$ & $3.51 \pm 0.01$ & $3.20 \pm 0.02$ \\
C18:3 9c 12c $15 c$ & $0.80 \pm 0.01$ & $0.70 \pm 0.03$ & $0.79 \pm 0.07$ & $0.77 \pm 0.05$ & $0.80 \pm 0.02$ & $0.70 \pm 0.09$ & $0.81 \pm 0.08$ & $0.77 \pm 0.03$ \\
CLA & $0.87 \pm 0.02$ & $0.86 \pm 0.05$ & $0.88 \pm 0.02$ & $0.86 \pm 0.03$ & $0.89 \pm 0.07$ & $0.86 \pm 0.04$ & $0.91 \pm 0.09$ & $0.83 \pm 0.04$ \\
\hline
\end{tabular}

aValues are expressed as means \pm SD of 3 independent assays. SCSFA - short chain saturated fatty acids, LCSFA - long chain saturated fatty acids, OBCFA - odd-and branched chain fatty acids, MUFA - monounsaturated fatty acids, PUFA - polyunsaturated fatty acids, CLA - conjugated linolenic acid.

\section{DISCUSSION}

Cookies with a high level of fats are willingly consumed owing to their high sensory values, however they are sources of undesirable compounds such as lipid oxidation products [Mildner-Szkudlarz et al., 2009; Caponio et al., 2013]. Recently, special interest has been given to the substances with antioxidant properties that naturally occur in plants. In the present study, a chokeberry polyphenol extract was used as an antioxidative agent due to the high content of polyphenolic compounds.

The primary lipid oxidation products are hydroperoxides, odorless and colorless but very labile species than can undergo degradation to generate a complex array of secondary products, such as aliphatic aldehydes, alcohols, ketones and hydrocarbons [Kolakowska, 2003]. Since the safety of lipid-containing food products depends on the degree to which oxidation had progressed, the simultaneous detection of primary and secondary lipid oxidation products helps to better characterize lipid quality. It is noteworthy that there is no ideal method to measure oxidative changes in food lipids. For this reason, the formation and degradation of both primary and secondary products of lipid oxidation should be monitored over time. The use of two or more methods assessing both primary and secondary oxidation products is, therefore, highly recommended [Pegg, 2001].
Measurement of PV is the most common method used to determine the content of hydroperoxides formed during initial stages of the oxidation cascade. Some differences in the course of oxidative changes between two types of the analyzed cookies were observed depending on both CPE content and time of storage (Figure 1). In general, butter cookies contained higher amounts of hydroperoxides than cookies with margarine. The safe value for PV for bakery fats is 3 meq of $\mathrm{O} / \mathrm{kg}$ of fat [Polish Standard, PN-A-86908:1966]. The content of primary lipid oxidation products in margarine cookies did not exceed this value even after 18 weeks of storage regardless of CPE content. In butter cookies with 100 and $250 \mathrm{mg}$ content of CPE after 9 weeks of storage the PV was higher than the recommended value. Compared to the control cookies, the antioxidative effect of polyphenols incorporation was observed in margarine cookies with all CPE contents, especially in these containing $100 \mathrm{mg}$ of CPE, because it was observed during the whole experiment. In butter cookies, only the content of $100 \mathrm{mg}$ of CPE caused the inhibition of oxidative changes till the $12^{\text {th }}$ week of storage.

The anisidine value (AV) is an indicator of the concentration of secondary lipid oxidation products generated during the decomposition of hydroperoxides [Shahidi \& Zhong, 2005]. These unstable compounds were consequently broken down by a free radical mechanism to give hydroxyl free radical and lots of other compounds - alcohols, aldehydes, ketones 

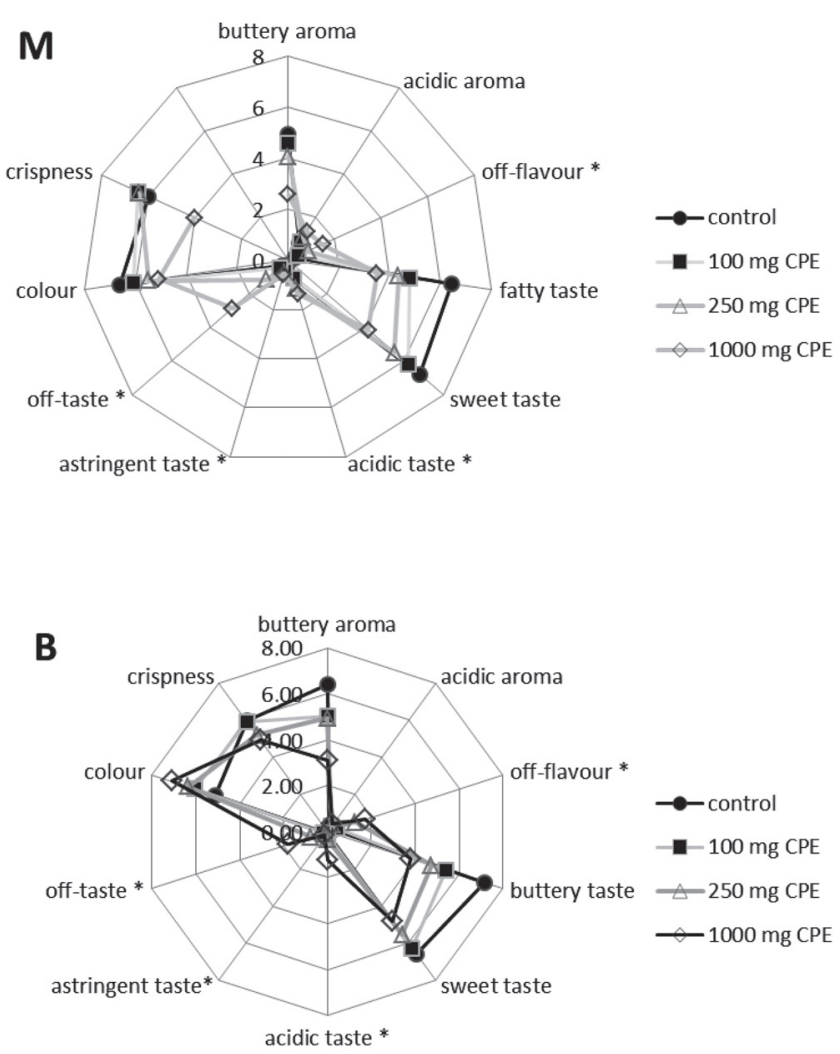

FIGURE 5. Sensory ratings of fresh margarine (M) and butter (B) cookies. Attributes differed significantly $(\mathrm{p}<0.05)$ regarding $\mathrm{CPE}$ content is marked by *.

and malonaldehyde, called secondary oxidation products [Darughe et al., 2012]. In the present study, in butter cookies initially an increase was observed in PV with time, which after reaching the maximum level began to decline. The PV decrease was accompanied by an increasing AV. This was due to the rapid decomposition of hydroperoxides to secondary oxidation products. This phenomenon was also confirmed by Aidos et al. [2002]. The high AV in cookies made with butter may be due to the content of volatile compounds responsible for the buttery flavor (Figure 2). Most of them are aldehydes and ketones, which can react with $p$-anisidine and overstate the results of AV determination [Stolyhwo \& Rutkowska, 2013]. The proposed permissible concentration of secondary lipid oxidation products measured as AV is 8 [Podmore, 1992] and in case of margarine cookies it was only slightly exceeded at the end of storage in the cookies with 100 and $250 \mathrm{mg}$ of CPE. The highest level of CPE potentiated the generation of secondary lipid oxidation products. This observation is in agreement with results of Darughe et al. [2012] who found that coriander essential oil rich in antioxidants in high concentration may act as a pro-oxidant. The antioxidative effect of chokeberry polyphenolic extract was observed in cookies containing 100 and $250 \mathrm{mg}$ of CPE when compared to the control samples. In butter cookies, the reference value was exceeded only in cookies containing 250 and $1000 \mathrm{mg}$ of CPE after 9 weeks of storage. The inhibitory effect of CPE was shown in the cookies with $100 \mathrm{mg}$ of the chokeberry extract.

$\mathrm{PV}$ and $\mathrm{AV}$ reflect the oxidation level at early and later stages of oxidation reaction, respectively. TOTOX values reflect con- tents of both hydroperoxides and their breakdown products, and provide a better estimation of the progressive oxidative deterioration of fats e.g. during storage [Shahidi \& Zhong, 2005; Mildner-Szkudlarz et al., 2009]. Exactly the same tendency as for $\mathrm{AV}$ was observed for TOTOX in the case of both margarine and butter cookies. Also by comparing to the control samples, the antioxidative effects were shown for butter cookies containing $100 \mathrm{mg}$ of $\mathrm{CPE}$ and in margarine cookies with 100 and $250 \mathrm{mg}$ of CPE.

The TBARS value measures the formation of secondary oxidation products reacting with thiobarbituric acid (mainly malondialdehyde - MDA) [Darughe et al., 2012]. During lipid oxidation, MDA, a minor component of fatty acids with 3 or more double bonds, is formed as a result of the degradation of PUFA. MDA is probably formed from trienes by $\alpha$ - or $\beta$-unsaturated peroxides [Wheatley, 2000].

In margarine cookies (Figure 3), the control samples exhibited the highest TBARS content throughout the experimental period, showing great oxidative changes. Cookies containing CPE had a lower concentration of TBARS, which is in agreement with results of Darughe et al. [2012] and Izzreen \& Noriham [2011] who evaluated antioxidative properties of coriander essential oil and some Malaysian herbal extract, respectively. In the case of both margarine and butter cookies, the samples with the highest amount of CPE were safe for consumption over the whole storage period, because the level of TBARS was lower than $57.6 \mu \mathrm{g} \mathrm{MDA} / \mathrm{g}$ of fat, which is a reference value for rancidity [Izzreen \& Noriham, 2011].

Interestingly, in both margarine and butter cookies the addition of $1000 \mathrm{mg}$ of CPE inhibited the formation of TBARS to a greater extent than the lower amounts. The opposite situation was observed in case of secondary oxidation products measured as AV, where the highest level of polyphenol extract incorporated into cookies potentiated the oxidative changes. This observation leads to the conclusion that one method is insufficient to determine oxidative changes in food lipids. Many other substances may react with the TBA reagent and contribute to the increased absorption, causing an overestimation of the intensity of color complex. Interferences may come from additional absorption of other alkanals, 2-alkenals, 2,4-alkadienals, ketones, ketosteroids, acids, esters, proteins, sucrose, urea, pyridines and pyrimidines, also referred to as TBARS [Shahidi \& Zhong, 2005]. Due to the non-specificity of the TBARS test, its results reflect the rancidity of food better than other conventional methods, especially in the case of off-flavors which are caused by volatiles from lipids and are affected by products of lipids interaction with nitrogenous compounds [Kolakowska, 2003]. It is highly advisable to conduct further studies in this area to explain this phenomenon.

Measurement of changes in the fatty acid composition is useful for the identification of FA that are involved in the oxidation process. It is an indirect indicator of the extent of oxidation. During the storage of experimental cookies, losses were observed in the MUFA and PUFA content (Tables 2 and 3). A decreasing content of unsaturated FA was noticeable especially after the $18^{\text {th }}$ week of storage. The effect of storage is more evident in the case of $\alpha$-linolenic acid (ALA, $c-9 c-12 c-15$ C18:3) than in LA (linoleic acid, $c-9 c-12$ C18:2) because of the higher number of double bonds in the chain 
[Frankel, 2005]. FA containing unsaturated bonds in their chain are susceptible to oxidation and their content decreases throughout storage, while the concentration of oxidation products increases [Izzreen \& Noriham, 2011]. Changes in the ALA content are confirmed by the TBARS level in lipids extracted from cookies, while MDA is a product of oxidation of FA with 3 or more double bonds.

As evidenced by the two-way ANOVA, both CPE content and storage period had a significant impact on the quality of fat in the experimental cookies. Also Maisuthisakul et al. [2007] found that storage time was a significant factor for oxidative changes in rice crackers enriched with Cratoxylum formosum extract.

Chokeberry contains high amounts of proanthocyanidins which impart a specific astringent and bitter taste. This fruit is also exceptionally rich in anthocyanins, which is responsible for its deep, purple color [Wilkes et al., 2014]. Therefore, depending on $\mathrm{pH}$ conditions, it may adversely affect the taste and color of confectionery products. That is why the sensory assessment of cookies enriched in CPE was conducted by the panel of experts. The increase in the level of CPE incorporated into cookies resulted in significant growth of intensity of astringent taste, acidic taste, off-taste and off-flavour (Figure 5). The sensory panel scored the highest intensity of above mentioned attributed in cookies containing $1000 \mathrm{mg}$ of CPE. Our results are in agreement with these obtained by Górecka et al. [2010], who used raspberry pomace for cookies enrichment. Taking into account that desired by the consumers sweet and buttery taste were less intense, the evaluation of consumer acceptance of cookies with $\mathrm{CPE}$ seems to be of great importance.

\section{CONCLUSION}

Assessment of oxidative quality indicators of lipids extracted from cookies enriched with different levels of chokeberry polyphenols suggest that they may be used to extend the shelflife of cookies. Regarding the oxidation degree, margarine cookies containing 100 and $250 \mathrm{mg}$ of CPE seem to be safe for consumption within 9 weeks. It is also safe to incorporate $1000 \mathrm{mg}$ of CPE to butter cookies when the time of storage is no longer than 9 weeks. However, the highest CPE content may decrease consumer acceptability of cookies, due to higher intensity of astringent and acidic taste as well as off-flavours.

\section{ACKNOWLEDGEMENTS}

Authors declare no conflict of interest. The research was carried out in the framework of the research task financed by funds of the Faculty of Human Nutrition and Consumer Sciences of Warsaw University of Life Sciences (WULS-SGGW) for the young scientist no. 505-10-10050052.

\section{REFERENCES}

1. Abdel-Samie M.A.S, Wan J., Huang W., Chung O.K., Xu B., Effects of cumin and ginger as antioxidants on dough mixing properties and cookie quality. Cereal Chem., 2010, 87, 454-460.
2. Aidos I., Lourenco S., van Der Padt A., Luten J.B., Boom R.M., Stability of crude herring oil produced from fresh byproducts: Influence of temperature during storage. J. Food Sci., 2002, 67, 3341-3320.

3. AOCS 2000 Official Method Ce 2-66. Preparation of methyl esters of fatty acids. American Oil Chemists' Society. USA

4. Badei A.Z.M., El-Akel A.T.M., Faheid S.M.M., Mahmoud B.S.M., Application of some spices in flavoring and preservation of cookies: antioxidant properties of cardamom, cinnamon and clove. Deut. Lebensm. Rundsch., 2002, 98, 176-183.

5. Barylko-Pikielna N., Matuszewska I., Analiza sensoryczna żywności. Podtsawy, metody, zastosowanie. 2014, PTTŻ, Kraków, pp.163-180 (in Polish).

6. Basuny A.M., Nasef S.L., Mahmoud E.A.M., Arafat S.M., Use of medicinal and aromatic plants for increasing quality of some bakery products. Int. Sci. Invest. J., 2012, 1, 1-23.

7. Bhanger M.L., Iqbal S., Anwar F., Imran M., Akhtar M., Zia-ul-Haq M., Antioxidant potential of rice bran extracts and its effects on stabilization of cookies under ambient storage. Int. J. Food. Sci. Tech., 2008, 43, 779-786.

8. Bialek M., Rutkowska J., Hallmann E., Black chokeberry Aronia melanocarpa as potential component of functional food. Żywność. Nauka. Technologia. Jakość. 2012, 19, 6, 21-30 (in Polish, English abstract).

9. Broncel M., Kozirog M., Duchnowicz P., Koter-Michalak M., Sikora J., Chojnowska -Jezierska J., Aroniamelanocarpa extract reduces blood pressure, serum endothelin, lipid, and oxidative stress marker levels in patients with metabolic syndrome. Med. Sci.Monit., 2010, 16, 28-34.

10. Caponio F., Giarnetti M., Summo C., Paradiso V., Cosmai L., Gomes T., A comparative study on oxidative and hydrolytic stability of monovarietal extra virgin olive oil in bakery products. Food Res. Int., 2013, 54, 1995-2000.

11. Darughe F., Barzegar M., Sahari M.A., Antioxidant and antifungal activity of coriander (Coriandrum sativum L.) essential oil cake. Int. Food Res. J., 2012, 19, 1253-1260.

12. Denev P.N., Kratchanov C.G., Ciz M., Lojek A., Kratchanova M.G., Bioavailability and antioxidant activity of black chokeberry (Aroniamelanocarpa) polyphenols: in vitro and in vivo evidences and possible mechanisms of action: a review. Comp. Rev. Food Sci. Food Safety, 2012, 11, 471-489.

13. Frankel E.N., Methods to determine extent of lipid oxidation. 2005. in: Lipid Oxidation. $2^{\text {nd }}$ Ed. Bridgewater, England: Oily Press, pp. 99-127.

14. Frankel E.N., Antioxidants in lipid foods and their impact on food quality. Food Chem., 1996, 57, 51-55.

15. Gorecka D., Pacholek B., Dziedzic K., Gorecka M., Raspberry pomace as a potential fiber source for cookies enrichment. Acta Sci. Pol., Technol. Aliment., 2010, 9, 451-462.

16. Huang W-N., Li Z-N., Acrylamide inhibition in cookies using natural antioxidants. Food Sci., 2011, 32, 129-140.

17. Ishida H., Suzuno H., Innami S., Maekawa A., Tadokoro T., Quality, preference characteristic and preservation stability of cookies added with sweet potato leaf powder. Food Preserv. Sci., 2003, 29, 75-81.

18. ISO 2001. Method 3960. Animal and vegetable fats and oils. Determination of peroxide value. International Organization for Standarization: Geneva, Switzerland. 
19. ISO 2006. Method 6885. Edible vegetable fats. Determination of anisidine value. International Organization for Standarization: Geneva, Switzerland.

20. Isobe Y., Kase Y., Narita M., Komiya T., Antioxidative activity of a polyphenol extract from Feijoa Sellowiana Berg and its application to cookies. J. Home Econ. Jap., 2004, 55, 799-804.

21. Izzreen I., Noriham A., Evaluation of the antioxidant potential of some Malaysian herbal aqueous extracts as compared with synthetic antioxidants and ascorbic acid in cakes. Int. Food Res. J., 2011, 18, 583-587.

22. Kolakowska A., Lipid oxidation in food systems. 2003. in: Chemical and Functional Properties of Food Lipids. (eds. Z.E.Sikorski, A. Kolakowska). Boca Raton: CRC Press, Florida, pp. 133-160.

23. Kozlowska M., Zbikowska A., Gruczynska E., Zontala K., Poltorak A., Effects of spice extracts on lipid fraction oxidative stability of cookies investigated by DSC. J. Therm. Anal. Calorim., 2014, 118, 1697-1705.

24. Lee JE., Kim G-S., Park S., Kim Y-H., Kim M-B., Lee WS., Jeong SW., Lee SJ., Jin JS., Shin SC., Determination of chokeberry (Aronia melanocarpa) polyphenol components using liquid chromatography-tandem mass spectrometry: Overall contribution to antioxidant activity. Food Chem., 2014, 146, 1-5.

25. Maisuthisakul P., Gordon M.H., Pongsawatmani R., Suttajit M., Enhancing the oxidative stability of rice crackers by addition of the ethanolic extract of phytochemicals from Cratoxylum formosum dyer. Asia Pac. J. Clin. Nutr., 2007, 16 (Suppl. 1), 37-42.

26. Marquez-Ruiz G., Garcia-Martinez M.C., Holgado F., Changes and effects of dietary oxidized lipids in the gastrointestinal tract. Lipids Insights, 2008, 2, 11-19.

27. Martinez-Tome M., Jimenez A.M., Ruggieri S., Frega N., Strabbioli R., Murcia M.A., Antioxidant properties of Mediterranean spices compared with common food additives. J. Food Protect., 2001, 64, 1412-1419.

28. Mildner-Szkudlarz S., Zawirska-Wojtasiak R., Obuchowski W., Goslinski M., Evaluation of antioxidant activity of green tea extract and its effect on the biscuits lipid fraction oxidative stability. J. Food Sci., 2009, 74, S362-S370.

29. Nanditha B.R., Jena B.S., Prabhasankar P., Influence of natural antioxidants and their carry-through property in biscuit processing. J. Sci. Food Agr., 2009, 89, 288-298.

30. Ohkawa H., Ohishi N., Yagi K., Assay for lipid peroxides in animal tissues by thiobarbituric acid reaction. Anal. Biochem., 1979, 95, 351-358.

31. Oszmianski J., Scientific expert opinion about ARONOX, [http:// www.cislog.pl/allegro/doc/Aronox_opinia1.pdf].

32. Oszmianski J., Wojdylo A., Aronia melanocarpa phenolics and their antioxidant activity. Eur. Food. Res. Technol., 2005, 221, 809-813.

33. Pegg R.B., Measurement of Primary Oxidation Products. Current Protocols in Food Analytical Chemistry. 2001, Unit D2.1.1 - D2.1.15. John Wiley \& Sons.
34. Podmore J,. Recent Advances in Chemistry and Technology of Fats and Oils. 1992. Elsevier Applied Science, London, p. 172.

35. Polish Standard, PN-A-88021:1971 Confectionery products determination of fat content.

36. Polish Standard, PN-A-86908:1966P Edible vegetable fats - refined vegetable oils.

37. Polish Standard, PN-ISO 4121:1998 Sensory analysis - Methodology - Evaluation of food products by using the scaling method.

38. Reddy V., Urooj A., Kumar A., Evaluation of antioxidant activity of some plant extracts and their application in biscuits. Food Chem., 2005, 90, 317-321.

39. Shahidi F., Zhong Y., Lipid oxidation: Measurement Methods. 2005. in: Bailey's Industrial Oil and Fat Products (ed. F. Shahidi,). Sixth Edition, Six Volume Sct., John Wiley \& Sons, pp. 357-385.

40. StatSoft, Inc. (2010). STATISTICA (data analysis software system), version 9.1.

41. Stolyhwo A., Rutkowska J., Milk fat: structure, composition and health benefits. 2013, in: Food Chemistry, vol. 3 (ed. Z.E. Sikorski). WNT, Warszawa, pp. 39-88 (in Polish).

42. Sudha M.L., Baskaran V., Leelavathi K., Apple pomace as a source of dietary fiber and polyphenols and its effect on the rheological characteristics and cake making. Food Chem., 2007, 104, 686-692.

43. Šavikin K., Zdunić G., Janković T., Godevac D., Stanojković T., Pljevljakušić D., Berry fruit teas: Phenolic composition and cytotoxic activity. Food Res. Int., 2014, 62, 677-683.

44. Taheri R., Connolly B.A., Brand M.H., Bolling B.W., Underutilized chokeberry (Aronia melanocarpa, Aronia arbutifolia, Aronia prunifolia) accessions are rich sources of anthocyanins, flavonoids, hydroxycinnamic acids and proanthocyanidins. J. Agr. Food Chem., 2013, 61, 8581-8588.

45. Valenzuela A., Sanhueza J., Nieto S., Natural antioxidants in functional foods: from food safety to health benefits. Grasas Aceites, 2003, 54, 295-303.

46. Vergara-Valencia N., Granados-Perez E., Agama-Acevedo E., Tovar J., Ruales J., Bello-Perez L.A., Fiber concentrate from mango fruit: Characterization, associated antioxidant capacity and application as bakery product ingredient. LWT-Food Sci. Technol., 2007, 40, 722-729.

47. Wheatley R.A., Some recent trends in the analytical chemistry of lipid peroxidation. Trends Anal. Chem., 2000, 19, 617-628.

48. Wilkes K., Howard L.R., Brownmiller C., Prior R.L., Changes in Chokeberry (Aronia melanocarpa L.) polyphenols during juice processing and storage. J. Agric. Food Chem., 2014, 62, 4018-4025 .

Submitted: 2 December 2014. Revised: 28 January 2015. Accepted: 24 February 2015. Published on-line: 21 October 2015. 